\title{
Ion Kinetic Energy Modulation for Improved Ion Trapping in Electrospray Ionization Fourier Transform Ion Cyclotron Resonance Mass Spectrometry
}

\author{
C. L. Hendrickson, J. J. Drader, and D. A. Laude, Jr. \\ Department of Chemistry and Biochemistry, The University of Texas at Austın, Austın, Texas, USA
}

\begin{abstract}
A new technique for manipulating the kinetic energy distribution of electrospray ions that arrive at a Fourier transform ion cyclotron resonance trapped-ion cell is presented. Narrow kinetic energy distributions can complicate the selection of appropriate trapping conditions for electrospray ions and introduce charge discrimination in resulting mass spectra. Modulation of the applied skımmer potential controllably broadens the kinetic energy distribution, which improves the reproducibility of acquired spectra and elıminates charge discrimination. Mass spectra of horse heart cytochrome $c$ are presented to demonstrate the utility of the technique. For example, applied static skımmer potentials of 12 and $9 \mathrm{~V}$ yreld charge state distributions ranging from $[\mathrm{M}+19 \mathrm{H}]^{+19}$ to $[\mathrm{M}+12 \mathrm{H}]^{+12}$ and $[\mathrm{M}+15 \mathrm{H}]^{+15}$ to $[\mathrm{M}+7 \mathrm{H}]^{+7}$, respectively. A $12 \pm 2 \mathrm{~V}, 100-\mathrm{Hz}$ modulation of the skimmer potential yields an electrospray spectrum with charge states that range from $[\mathrm{M}+19 \mathrm{H}]^{+19}$ to $[\mathrm{M}+7 \mathrm{H}]^{+7}$, which is more representative of the source distribution. (J Am Soc Mass Spectrom 1995, 6, 76-79)
\end{abstract}

$\mathrm{I}$ electrospray ionization mass spectrometry [1-3] it has been established that there is a strong correlation between the number of charges on an ion and ion kınetic energy [4-6]. Specifically, the kinetic energy per unit charge derived from the gas expansion scales inversely with the number of charges, in contrast to the kinetic energy per unit charge achieved as a result of applied fields, which is charge independent. The effect of this kinetic energy spread on electrospray spectra depends on the type of mass analysis employed For example, the vast majority of electrospray mass spectra have been acquired by using quadrupole mass filters. Relative abundances measured with these instruments are largely independent of kinetic energy, so any kinetic energy-based discriminatory effects would be expected to be minimal. However, these instruments do exhibit a limited upper mass range, and it is likely that electrospray mass spectra have tended to favor detection of the more highly charged, lower mass-to-charge ratio ions [7].

The implementation of electrospray ionization on Fourier transform ion cyclotron resonance (FTICR)

Address repnint requests to Professor David A Laude, Jr, Department of Chemistry and Biochemistry, Unuversity of Texas at Austın, Austun, TX 78712 mass spectrometers [8-12] has spurred an increasing awareness of kinetic energy effects on electrospray mass spectra This is because the potential applied to the trapping electrodes of the FTICR trapped-1on cell must be tuned to the kinetic energy per charge of an arriving ion to confine the ion for detection [13]. Differences in ion kinetic energy can actually be used to select between different proteins or even between conformations of the same protein $[6,14]$.

Considerable effort is usually made to reduce the kinehc energy spread of an electrospray ion population with the aim of increasing spectrometer sensitivity. With our spectrometer, which generates electrospray ions in a strong magnetic field, the need for elaborate focusing of ion trajectories is arrested and a very narrow kinetic energy distribution of ions can be delivered to the cell [14]. A difficulty often arises however in selecting appropriate conditions for trapping ions, especially when examining unknown samples.

A solution that we have found for increasing the reliability of ion trapping is to modulate the potential applied to the skimmer of the electrospray source. The obvious advantage from our initial perspective was that the kinetic energy distribution of the electrosprayed ions would be controllably broadened, thus simplifying the selection of trapping parameters. Although the improvement in reproducibslity was re- 
markable, we soon realized that a more important benefit was the elimination of charge-dependent kinetic energy effects in the sampling of electrospray ion populations. Previously we had proposed the more technically difficult process of reduction of the gas expansion contribution to the ion kinetic energy [14]. Modulation of the applied skimmer potential is a far simpler procedure which we believe guarantees that a more quantitative representation of electrospray ions leaving the source is delivered to the mass analyzer for detection.

\section{Experimental}

The electrospray 1onization mass spectrometer used for all experiments is described in detall elsewhere $[6,9$, $14,15]$. Briefly, electrospray ions are formed at atmosphere in a Chait-type source [16] positioned in the bore of a 3.0-T superconducting magnet. Differential pumping across a series of concentric vacuum chambers reduces the system pressure to $10^{-9}$ torr at the trapped-ion cell positioned $15 \mathrm{~cm}$ away in the center of the magnet. Ion kinetic energy is determined by a supersonic gas expansion across the heated metal capillary and $250-\mu \mathrm{m}$ skımmer and by the potential applied to the skimmer, which was typically in the 5- to $15-\mathrm{V}$ range. Typical trap potentials used to capture ions were between 5 and $10 \mathrm{~V}$. Ions were excited by using a $70-V_{\mathrm{p}-\mathrm{p}}$ chirp swept at $400 \mathrm{~Hz} / \mu$ s and $16 \mathrm{k}$ data points were digitized using a $600-\mathrm{kHz}$ bandwidth. The resulting transients were baseline corrected and zero padded prior to magnitude-mode Fourier transformation.

The only modification to the spectrometer for the electrospray spectra to be presented was the addition of an ac voltage to the standard dc skimmer potential This was accomplished by using the summing amplifier shown in Figure 1. The frequency of the ac potentral was variable from 0 to $100 \mathrm{kHz}$. For suitable kinetic energy broadening to occur, the period of the ac waveform was required to be less than the injection

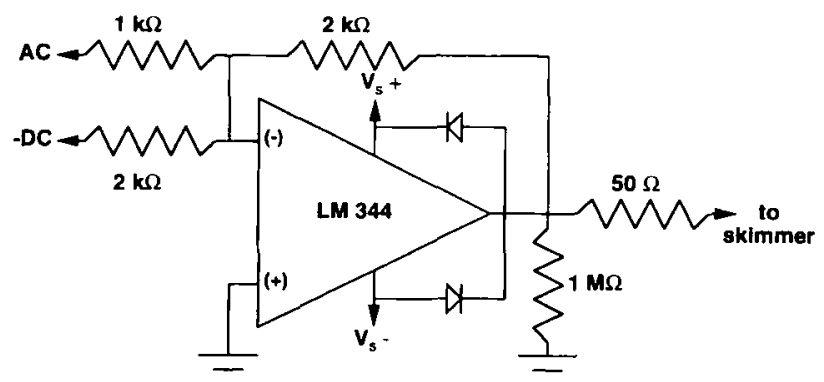

Figure 1. Schematic diagram of the summing amplifier used to modulate the applied skimmer potentral. Diodes between the output and the supply voltages and the $50-\Omega$ and 1-M $\Omega$ resistors protect the amplifier from any accidentally applied voltages at the skımmer cone time, which was typically $200 \mathrm{~ms}$ For our purposes, 5to $100-\mathrm{Hz}$ frequencies were adequate.

\section{Results and Discussion}

Presented in Figure 2 are representative electrospray FTICR mass spectra for horse heart cytochrome $c$ with different potentials applied to the skimmer. The mass spectrum in Figure 2a was generated by using a 12-V skımmer potential with the trapping potential opt1mized for maximum FTICR signal. The symmetrical charge distribution centered around +16 charges and ranging from +19 to +12 charges is representative of those most often observed for cytochrome $c$ on our instrument. However, if the applied skımmer potential is adjusted to $9 \mathrm{~V}$, a very different electrospray spectrum (shown in Figure $2 b$ ) is generated. In this case a collection of lower charge state ions extending from +15 to +7 charges is observed. These spectra demonstrate just how significant the charge discrimination can be in FTICR. It is interesting to note that a wide variety of charge state distributions of cytochrome $c$ from the use of FTICR and other mass analyzers have been reported $[1-3,12,13,17-20]$.

Presented in Figure 2c is a spectrum of cytochrome $c$ with a $4-\mathrm{V}_{\mathrm{p}-\mathrm{p}}, 100-\mathrm{Hz}$ ac potential added to the $12-\mathrm{V}$ dc skimmer potential Conditions are otherwise identical to those in Figure $2 \mathrm{~b}$. The range of applied skımmer potentrals from 10 to $14 \mathrm{~V}$ is evidently sufficient to generate a spread of kınetic energies to ensure that lons over a 13 charge state distribution achieve a kinetic energy per unit charge accommodated by the trapping conditions of the trapped-ion cell The symmetrical charge distribution in Figure $2 c$ retains the base peak selected in Figure 2a when trapping conditions were optimized for maximum signal. However, the lower charge state ions represented in the spectrum in Figure $2 \mathrm{~b}$ are also present but assume a more probable relative abundance when integrated into the high charge distribution. We contend that this electrospray ion population more accurately represents the actual charge distribution of ions exiting the source.

Furthermore, it should be noted that application of the modulation does not necessarily increase the charge state distribution. By carefully controlling the amplitudes of the ac and dc components of the applied skımmer potential, the number of charge states observed can be increased or diminished We have observed as many as 14 charge states of cytochrome $c$ and as few as 3 . It is not unreasonable to believe that more selective charge state distributions are possible.

Work is in progress to better evaluate the quantitative aspects of FTICR mass spectra when a modulated skimmer potential is employed. This simple modification should improve the ability to evaluate the effect of electrospray source conditions on charge state distributions and the facllity with which lower charge state electrospray species are observed. For FTICR applications that involve poorly characterized samples, the 
a

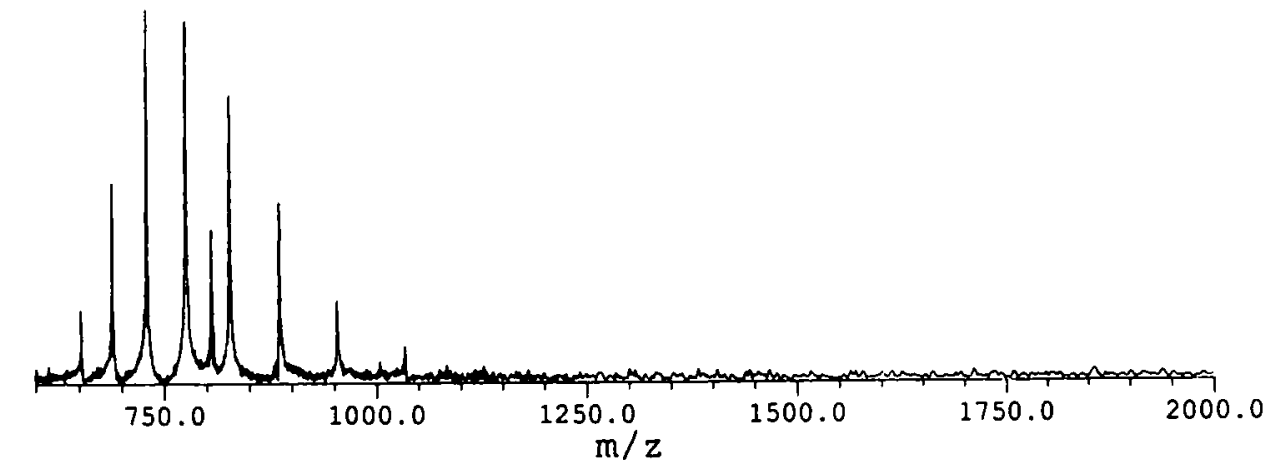

b

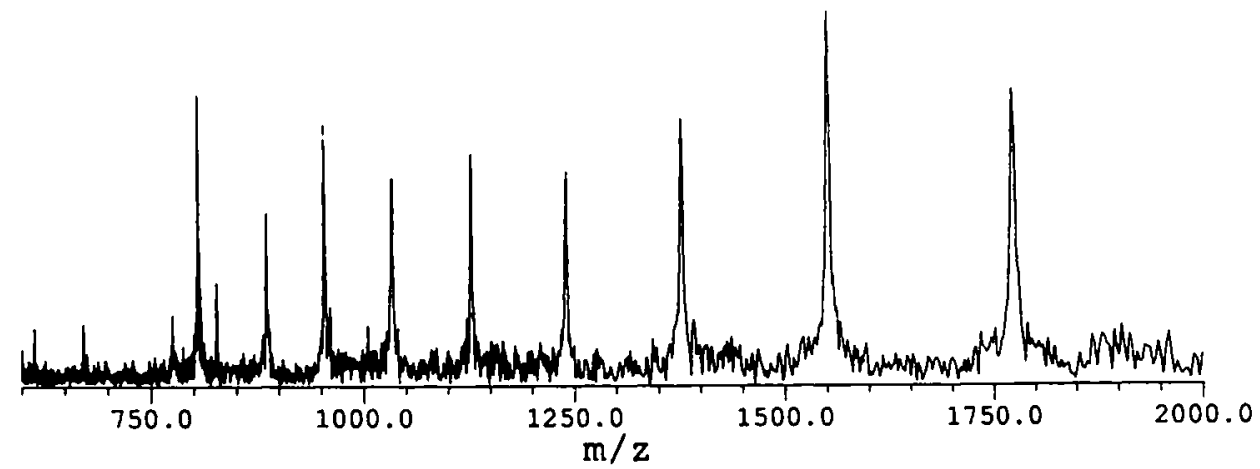

c

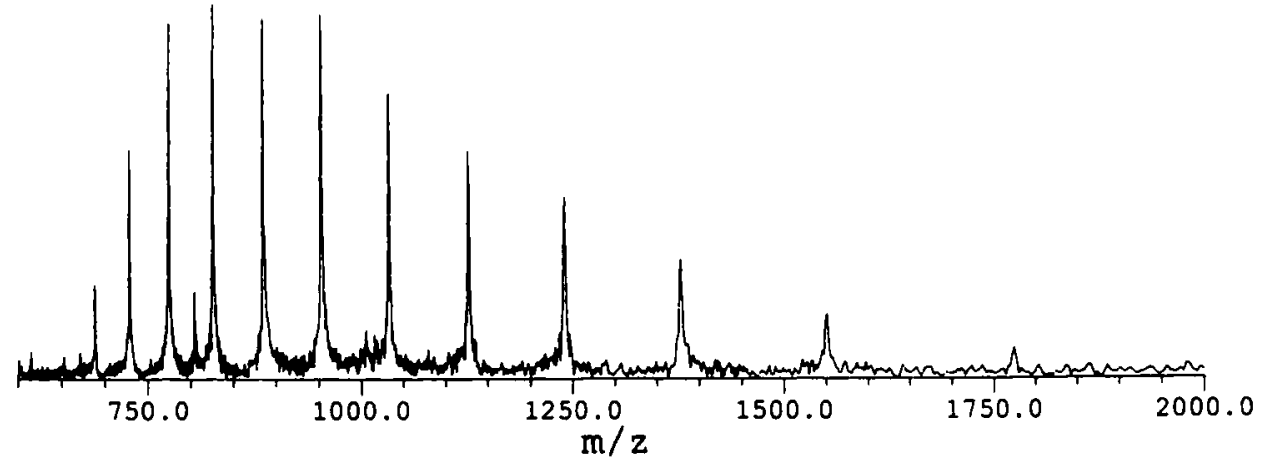

Figure 2. Comparison electrospray tonuzation-FTICR spectra of horse heart cytochrome $c$ taken with (a) a 12-V applied skummer potentral, (b) a 9-V skimmer potential, and (c) a $12 \pm 2 \mathrm{~V}, 100-\mathrm{Hz}$ skimmer potentral.

modulated skimmer affords significantly enhanced performance by ensuring that appropriate conditions for trapping are achieved. Finally, the effect of modulation on other electrospray ionization-mass spectrometry instruments is being investigated.

\section{Acknowledgment}

This work was supported by the Welch Foundation, the Texas Advanced Research Program, the National Instrtutes of Health, and the National Science Foundation.

\section{References}

1. Smith, R. D.; Loo, J. A.; Ogorzalek Loo, R. R.; Busman, M.; Udseth, H. R. Mass Spectrom. Rev. 1991, 10, 359-451.
2. Fenn, J. B.; Mann, M.; Meng, C. K ; Wong, S. F.; Whutehouse, C. M. Mass Spectrom. Rev 1990, 9, 37-70.

3. Smith, R. D.; Loo, J. A., Edmonds, C. G.; Barinaga, C. J, Udseth, H. R. Anal. Chem 1990, 62, 882-899.

4. Dole, M.; Mack, L L., Hınes, R. L ; Mobley, R. C., Ferguson, L. D.; Alice, M. B. J. Chem Phys 1968, 49, 2240-2249

5 Feng, R.; Konishi, Y. Presented at the 12th International Mass Spectrometry Conference, Amsterdam, The Netherlands, August 26-30, 1991.

6. Hofstadler, S. A.; Beu, S. C.; Laude, D. A., Jr. Anal. Chem 1993, 65, 312-316.

7. Winger, B. E.; Light-Wahl, K. J.; Smith, R. D. I Am. Soc Mass Spectrom. 1992, 3, 624-630.

8. Henry, K. D.; McLafferty, F. W. Org Mass Spectrom. 1990, 25, 490-492.

9. Hofstadler, S. A., Laude, D. A., Jr. Anal Chem. 1992, 64, 569-572.

10. Beu, S. C.; Senko, M. W.; Quinn, J P., Wampler, F. W., III; McLafferty, F. W. J Am. Soc. Mass Spectrom. 1993, 4, 557-565. 
11. Winger, B. E ; Hofstadler, S. A., Bruce, ]. E., Udseth, H. R.; Smith, R D. J Am Soc Mass Spectrom 1993, 4, 566-577

12. IJames, C. F., Markey, S P / Am Soc. Mass Spectrom 1994, 5, 398-406

13 Hofstadler, S. A., Laude, D. A., Jr. J. Am Soc. Mass Spectrom. 1992, 3, 615-623.

14. Campbell, V. L., Guan, Z., Laude, D A., Jr J Am Soc. Mass Spectrom 1994, 5, 221-229.

15 Hofstadler, S. A., Schmidt, E. G, Guan, Z., Laude, D A., Jr. J Am. Soc Mass Spectrom, 1993, 4, 168-176.
16 Katta, V., Chowdhury, S. K.; Chait, B. T. I. Am Chem Soc. 1990, 112, 5348-5349

17. Fenn, J B ; Mann, M.; Meng, C. K., Wong, S. F., Whitehouse, C. M. Science 1989, 246, 64-71

18. Loo, J. A., Udseth, H. R., Smith, R D. Anal. Biochem. 1989, 179, 404-412.

19. Van Berkel, G. J., Glish, G. L., McLuckey, S. A. Anal Chem 1990, 62, 1284-1295.

20. Verentchikov, A. N., Ens, W., Standing, K. G. Presented at the 41st Annual ASMS Conference on Mass Spectrometry and Allied Topics, San Francisco, CA, May 31-June 4, 1993. 